\title{
TABLE OF CONTENTS
}

\section{Preface}

Glossary

Introduction by Woodrow Borah

Letters 1-8: October to December, 1839

Letters 8-23: January to June, 1840

Letters 23-30: July to December, 1840

Letters 30-41: January to June, 1841

Letters 41-51: July to December, 1841 303

Letters 52-54: January to April, 1842 
This page intentionally left blank 